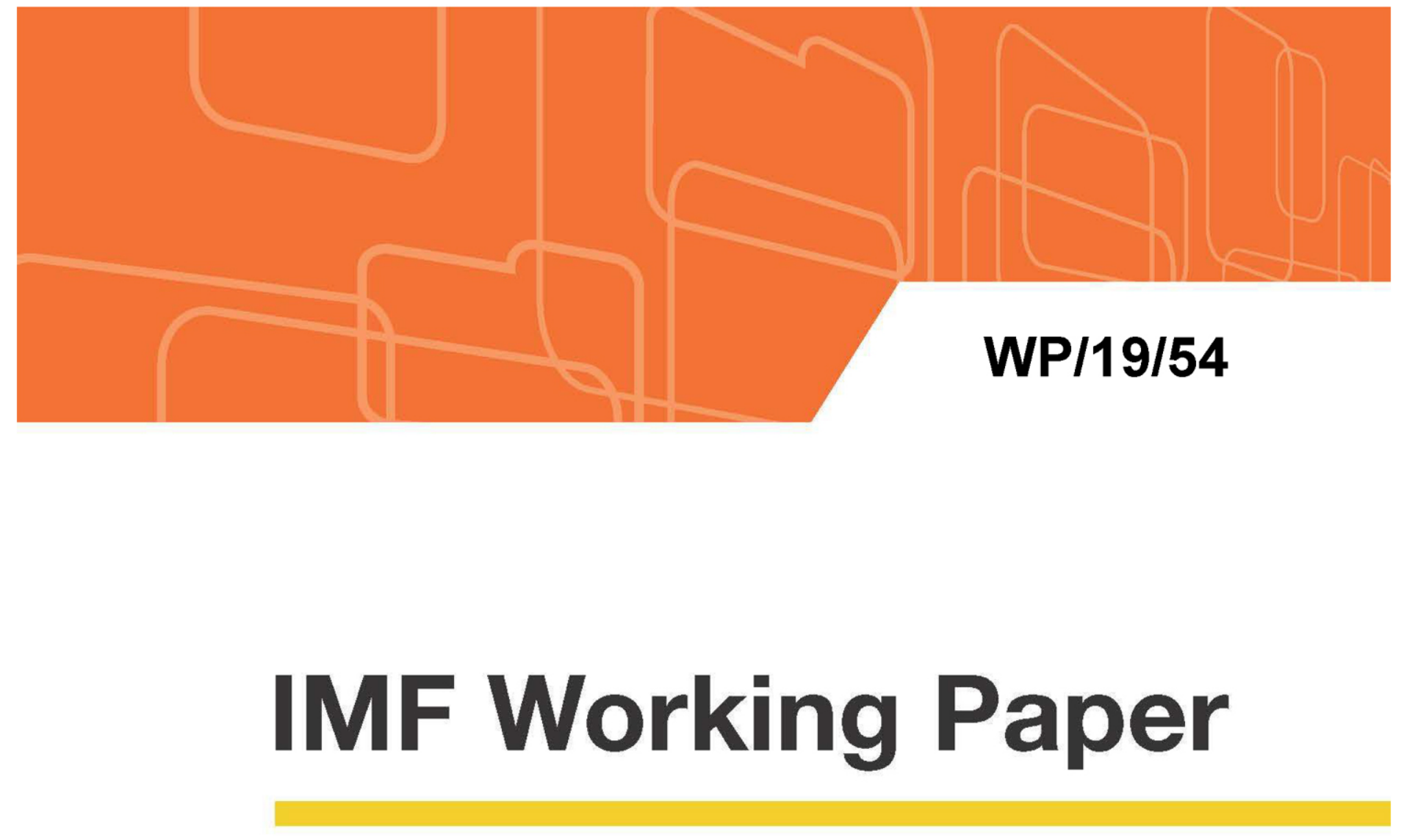

\title{
Policy Trade-Offs in Building Resilience to Natural Disasters: The Case of Saint Lucia
}

by Alessandro Cantelmo, Leo Bonato, Giovanni Melina, and Gonzalo Salinas

IMF Working Papers describe research in progress by the author(s) and are published to elicit comments and to encourage debate. The views expressed in IMF Working Papers are those of the author(s) and do not necessarily represent the views of the IMF, its Executive Board, or IMF management. 


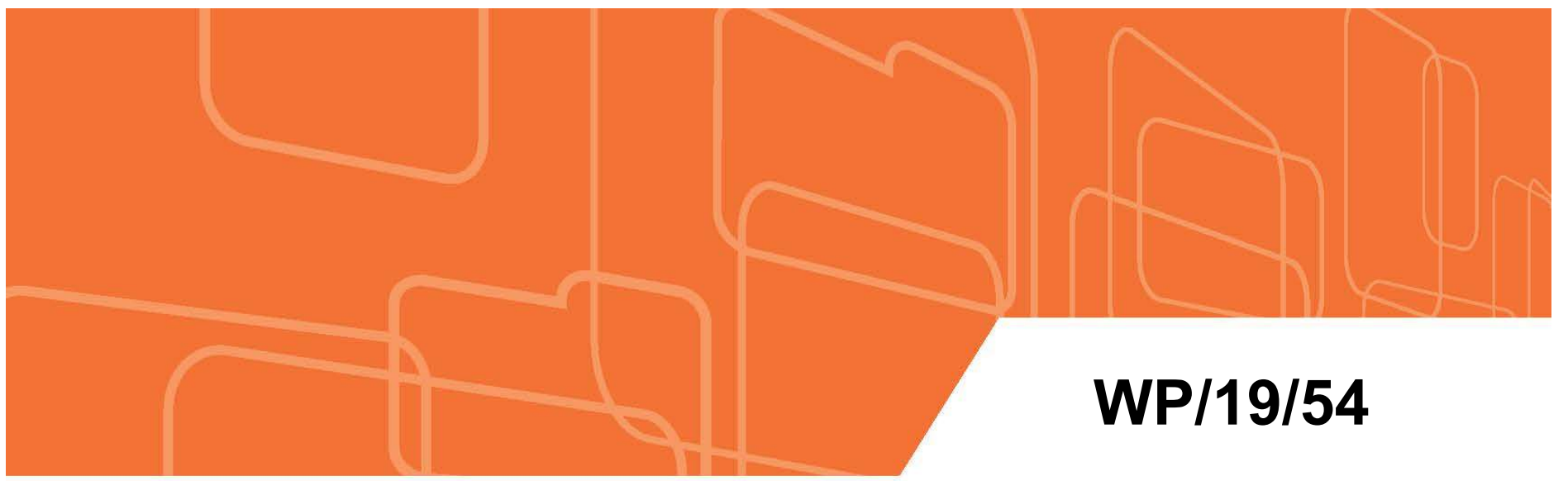

\section{IMF Working Paper}

\section{Policy Trade-Offs in Building Resilience to Natural Disasters: The Case of Saint Lucia}

by Alessandro Cantelmo, Leo Bonato, Giovanni Melina, and Gonzalo Salinas

IMF Working Papers describe research in progress by the author(s) and are published to elicit comments and to encourage debate. The views expressed in IMF Working Papers are those of the author(s) and do not necessarily represent the views of the IMF, its Executive Board, or IMF management. 


\title{
IMF Working Paper
}

Western Hemisphere Department and Research Department

\section{Policy Trade-Offs in Building Resilience to Natural Disasters: The Case of St. Lucia ${ }^{1}$ \\ Prepared by Alessandro Cantelmo, Leo Bonato, Giovanni Melina, and Gonzalo Salinas}

Authorized for distribution by Sònia Muñoz and Chris Papageorgiou

March 2019

IMF Working Papers describe research in progress by the author(s) and are published to elicit comments and to encourage debate. The views expressed in IMF Working Papers are those of the author(s) and do not necessarily represent the views of the IMF, its Executive Board, or IMF management.

\begin{abstract}
Resilience to climate change and natural disasters hinges on two fundamental elements: financial protection - insurance and self-insurance - and structural protection —investment in adaptation. Using a dynamic general equilibrium model calibrated to the St. Lucia's economy, this paper shows that both strategies considerably reduce the output loss from natural disasters and studies the conditions under which each of the two strategies provides the best protection. While structural protection normally delivers a larger payoff because of its direct dampening effect on the cost of disasters, financial protection is superior when liquidity constraints limit the ability of the government to rebuild public capital promptly. The estimated trade-off is very sensitive to the efficiency of public investment.
\end{abstract}

JEL Classification Numbers: Q54, Q58

Keywords: Climate Change; Natural Disasters and Their Management; Government Policy

Authors’ E-Mail Address: acantelmo@imf.org; lbonato@imf.org; gmelina@imf.org; gsalinas@imf.org

\footnotetext{
${ }^{1}$ We would like to thank Roland Kpodar, Sònia Muñoz, Chris Papageorgiou, Saad Quayyum, and participants at seminars at the Ministry of Finance of St. Lucia and IMF headquarters for their valuable comments. The usual disclaimer applies.
} 


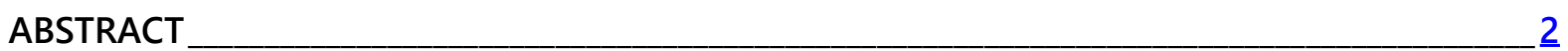

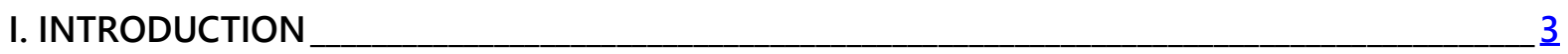

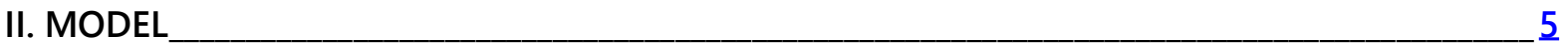

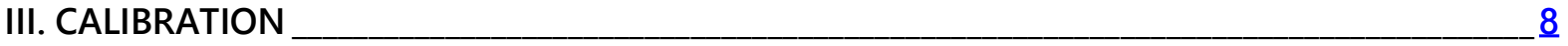

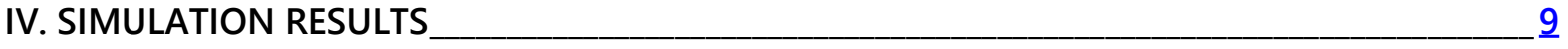

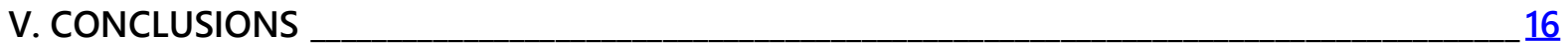

REFERENCES _________________________________________________________________

\section{FIGURES}

1. Above-Threshold Public Capital Reconstruction 11

2. Below-Threshold Public Capital Reconstruction

\section{TABLES}

1: Selected initial values (in percent) and calibrated parameters $\underline{8}$

2: Sensitivity of results to alternative calibrations 


\section{INTRODUCTION}

For many small developing states (SDS), building resilience to climate change and natural disasters is a key priority. Besides significant human and social costs, extreme weather and other catastrophic events have substantial macroeconomic implications in SDS, with an average annual cost of 2 percent of GDP, more than four times that for larger countries (International Monetary Fund, 2016). Despite the surge in donors' assistance that follows these events, disasters leave deep scars in the fiscal position, raising public debt and reducing fiscal space for government programs, including climate-related ones. Looking ahead, climate change is expected to affect SDS disproportionately by intensifying natural disasters and by more gradual effects such as rising sea levels and droughts. ${ }^{2}$ Appropriate policies that focus on risk reduction and preparedness are necessary to protect these countries from these events, improve their economic prospects, and exit the spiral of natural disasters/high public debt that many SDS, particularly in the Caribbean, have experienced.

Financial protection and structural protection are key elements of a two-pronged strategy to build resilience. Financial protection is a combination of self-insurance, risk-transfer instruments, and other financial tools that provide the government with the necessary liquidity immediately after the event, not only for relief purposes, but also to finance promptly the reconstruction. Financial protection has the additional benefit of reducing the government's contingent liabilities and building buffers that improve debt sustainability and reduce the risk premium on public debt. Structural protection is a series of actions that facilitate adaptation to climate change and minimize the impact of natural disasters. They include investment in resilient infrastructure and roadways, water supply systems, land use planning and management, and agriculture. One advantage of structural protection is that a more resilient public capital stock raises the marginal product of private capital, thereby stimulating private investment. However, protection policies have costs. Self-insurance has an opportunity cost as resources used to build fiscal buffers could be otherwise employed to reduce government debt and interest payments. Risk transfer instruments may be expensive, particularly if markets providing these instruments are shallow. As for structural protection, the price of resilient capital ("building back better") is significantly higher than that of standard capital.

The macroeconomic impact of these policies may be significant. Understanding costs and benefits of these policies is necessary to inform the strategy to build resilience and to ensure its consistency with fiscal constraints. While the literature on the macroeconomic impact of climate change and natural disasters is extensive, only a limited number of studies have looked at the effects of protection policies. Bevan and Adam (2016) use a dynamic general equilibrium model calibrated to Jamaica to identify significant benefits of disaster risk insurance in allowing faster rebuilding. However, the results of their simulations are

\footnotetext{
${ }^{2}$ Acevedo (2016) estimates that annual hurricane damages in the Caribbean can increase up to 77 percent by 2100 in an unmitigated climate change scenario. Under similar assumptions and time period, Acevedo and others (2018) estimate additional costs of 9 percent of GDP for a representative low-income country.
} 
inconclusive as these benefits are offset by actuarially unfair premia under a variety of conditions. Borenzstein, Cavallo, and Jeanne (2017) identify significant welfare gains from using catastrophe bonds as insurance against natural disasters, but conclude that these tools remain too costly to make them optimal for vulnerable countries. Marto, Papageorgiou, and Klyuev (2017) examine the benefits of investing in resilience and building fiscal buffers using Cyclone Pam in Vanuatu as a case study and find that investing in resilience provides a better output payoff than a mixed strategy of resilient investment and a savings fund. De Janvry, del Valle, and Sadoulet (2016) look at the impact of Mexico's Fund for Natural Disasters and find that municipalities with access to the Fund grew by $2-4$ percent faster than those with no access in the aftermath of natural disasters.

This paper uses a dynamic general equilibrium model that incorporates natural disasters to assess the macroeconomic impact of financial protection and structural protection, and the associated policy trade-offs. The model is built on Marto, Papageorgiou, and Klyuev (2017), modified in some important respects to reflect features specific to St. Lucia, which is our case study, and calibrated to the St. Lucian economy. ${ }^{3}$ One key difference is that the high level of public debt and the ECCU regional debt target of 60 percent of GDP by 2030 constrain St. Lucia in its ability to use government borrowing, which is reflected in the fiscal reaction function. In addition, to facilitate the comparison between policies, this paper (i) focuses on average disasters; and (ii) simplifies financing by assuming that all policies are funded by a grant of the same amount (including a do-nothing approach — where the grant is used to reduce public debt - against which financial protection and structural protection are benchmarked). Furthermore, we limit financial protection to a savings fund, ignoring other forms of insurance. These features of our approach allow us to focus our comparison on the benefits of a speedy reconstruction (financial protection) and those of a more resilient capital stock (structural protection) against a do-nothing approach.

Results of our simulations show that both financial protection and structural protection significantly reduce the output loss from natural disasters, and that the choice between both strategies significantly hinges on liquidity constraints and the efficiency of public investment. The rest of the paper is organized as follows. Section II presents the model; section III provides detail on calibration; Section IV reports the results of the simulations; and Section V concludes.

\section{MODEL}

Marto, Papageorgiou, and Klyuev (2017) extend the DIG model of Buffie and others (2012) to simulate the impact that Cyclone Pam had on Vanuatu in 2015, and study how the country could have built resilience to cope with it. ${ }^{4}$ DIG is a real, dynamic, two-sector small open

\footnotetext{
${ }^{3}$ A small island in the Atlantic hurricane belt, St. Lucia is very vulnerable to natural disasters and climate change (International Monetary Fund-World Bank, 2018).

${ }^{4}$ Here we outlay the key features of the model, while referring the reader to the original paper for a detailed description, and focus on our extensions.
} 
economy model with traded and non-traded goods sectors. In each sector, public capital is used as an input of production by perfectly competitive firms jointly with private capital and labor. The government has access to external and domestic debt while fiscal instruments ensure debt sustainability. Its extension incorporating natural disasters (DIGNAD, henceforth) allows the government to invest in both standard infrastructure and adaptation (resilient) capital, as well as in a savings fund. Adaptation capital is more resilient to climate change and natural disasters and helps preserve standard infrastructure and dampen the damages inflicted to the economy. ${ }^{5}$ Conversely, a savings fund immediately provides the necessary liquidity to start the reconstruction in the aftermath of the natural disaster. Natural disasters affect the economy by permanently damaging both public and private capital and by temporarily reducing total factor productivity. To study the policy trade-offs in building resilience to natural disasters, we extend the DIGNAD model further along five dimensions.

First, natural disasters are modeled as continuous shocks rather than one-time events. The economy is hit by a continuum of natural disasters of average magnitude with a permanent effect on GDP. Each year, a natural disaster occurs, destroying public and private capital and reducing TFP. Private agents and the government respond by reconstructing the destroyed capital stock, but the following year another natural disaster happens, causing further losses in capital and TFP. While Marto, Papageorgiou, and Klyuev (2017) focus on a known event, our modeling approach eliminates issues related with the specific timing of the event and simplifies the comparison between policies, making the exercise more relevant for the analysis of frequent average intensity disasters and the gradual impact of climate change.

Second, the government replenishes the savings fund regularly. After a natural disaster hits, the government withdraws the necessary resources from the fund to start the reconstruction without issuing new debt. However, to keep the liquidity buffers needed to withstand future natural disasters, the government replenishes the savings fund. We thus allow for endogenous dynamics of the savings fund as follows:

$$
\mathfrak{s}_{t}=\left(1+r^{f}\right) \mathfrak{s}_{t-1}+\mathfrak{s}_{t}^{\text {in }}-\mathfrak{s}_{t}^{o u t}
$$

where $r^{f}$ is a risk-free real interest rate earned on the stock of resources held in the previous period, while $\mathfrak{s}_{t}^{\text {in }}$ and $\mathfrak{s}_{t}^{\text {out }}$ are money injections and withdrawals, respectively. While money withdrawals equal the investment needed to reconstruct public capital, money injections are such that the government endogenously restores the savings fund up to the initial level, that is:

$$
\mathfrak{s}_{t}^{i n}=\phi^{\mathfrak{s}}\left(\mathfrak{s}_{t-1}-\mathfrak{s}_{0}\right),
$$

\footnotetext{
${ }^{5}$ Public adaptation capital enters the firms' production functions together with standard infrastructure, thus protecting also private infrastructure.
} 
where $\phi^{\mathfrak{s}}>1$ is a parameter governing the speed at which money is injected in response to the deviations of the stock of financial resources from the initial level $\mathfrak{s}_{0}$.

Third, the reconstruction of public capital is endogenous and limited by capacity and financial constraints. While Marto, Papageorgiou, and Klyuev (2017) define an exogenous path of public investment in response to the natural disaster, we let the government reconstruct the destroyed and depreciated public capital within the year according to a reaction function. In particular, investment in public standard $\left(i_{z i, t}\right)$ and adaptation $\left(i_{z a, t}\right)$ capital follow respectively:

$$
\begin{aligned}
i_{z i, t} & =\phi^{z}\left[z_{0}^{i}-\left(1-\delta_{z i}\right) z_{t-1}^{i}\right], \\
i_{z a, t} & =\phi^{z}\left[z_{0}^{a}-\left(1-\delta_{z a}\right) z_{t-1}^{a}\right],
\end{aligned}
$$

where $\delta_{z i}$ and $\delta_{z a}$ are the depreciation rates of public standard and resilient capital, respectively, while $z_{0}^{i}$ and $z_{0}^{a}$ denote their initial values. Equations (3) and (4) imply that, whenever the stock of the non-depreciated capital is lower than the initial stock, the government increases investment to restore it. Parameter $\phi^{z} \in[0,1]$ measures the speed of reconstruction of destroyed public capital, i.e. $\phi^{z}=1$ implies full reconstruction within the year in which the disaster occurs. Normally, $\phi^{z}<1$, i.e. the government can reconstruct only a fraction of the destroyed capital. In particular, the value of $\phi^{z}$ is limited by capacity constraints (the ability of the government to design and execute investment projects rapidly) as well as liquidity constraints (the availability of liquid funds for reconstruction either through a savings fund, other contingency funds, or budgetary reallocations).

Fourth, we impose a specific fiscal reaction function. In particular, we assume that the consumption tax will be adjusted as needed to attain the ECCU public debt target of 60 percent of GDP by 2030. To illustrate this point, equation (6) shows the law of motion of government debt where the only source of revenue is a consumption tax:

$$
\begin{gathered}
P_{z i, t} i_{z i, t}+P_{z a, t} i_{z a, t}+T_{t}+r_{t-1} P_{t} b_{t-1}+ \\
r_{d, t-1} d_{t-1}+r_{d c, t-1} d_{c, t-1}+\Delta \mathfrak{s}_{t} \leq P_{t} \Delta b_{t}+\Delta d_{t}+\Delta d_{c, t}+ \\
r^{f} \mathfrak{s}_{t-1}+\tau_{t}^{c} P_{t} c_{t} .
\end{gathered}
$$

The government has access to three forms of debt: (i) domestic $b_{t}$, (ii) external concessional $d_{t}$, and (iii) external commercial $d_{c, t}$, with $r_{t}, r_{d, t}$ and $r_{d c, t}$ being the respective net interest rates. In addition to the interest payments on debt, government expenditures occur through investment in standard and adaptation capital at the respective prices $P_{z i, t}$ and $P_{z a, t}$, and lump-sum transfers to households $T_{t}$. The government earns $\left(1+r^{f}\right)$ on the stock of savings held to withstand natural disasters and collects tax revenues $\tau_{t}^{C} c_{t}$ on consumption by setting the VAT rate $\tau_{t}^{C}$, so that the ECCU debt target of 60 percent of GDP is achieved by 2030. 
Finally, resilient capital better withstands natural disasters, but investing in it is more expensive. Investing in resilient capital entails a fiscal trade-off. Indeed, building a stock of resilient capital mitigates the damages inflicted by natural disasters. However, the price of materials, machinery and technologies able to withstand natural disasters is higher than the price of their standard counterparts, i.e. $P_{z a, t}=(1+\varepsilon) P_{z i, t}$, with $\varepsilon \in[0,1]$, in the government budget constraint. The government thus faces a trade-off between investing in resilient infrastructure while paying an additional cost, which entails further increasing tax revenues to achieve the targeted debt reduction.

\section{Calibration}

The model is calibrated to St. Lucia's economy with selected initial values set according to the data. ${ }^{6}$ Table 1 reports selected initial values and parameters calibrated to St. Lucia at an annual frequency. Public standard investment infrastructure as a share of GDP $\left(i_{z i, o}\right)$ is set at 3.9 percent, in accordance with the IMF World Economic Outlook (WEO) database (as of January 2018). Our baseline calibration assumes that there is no investment in adaptation

\begin{tabular}{lcc}
\multicolumn{2}{c}{ Table 2: Selected initial values (in percent) and calibrated parameters } \\
Definition & Parameter & Value \\
\hline & & \\
Initial values & $i_{z i, o}$ & 3.9 \\
& $i_{z a, o}$ & 0.0 \\
Public standard investment to GDP & $b_{o}$ & 35.3 \\
Public adaptation investment to GDP & $d_{o}$ & 20.4 \\
Public domestic debt to GDP & $d_{c, o}$ & 12.0 \\
Public concessional debt to GDP & $r_{o}$ & 5.2 \\
Public external (commercial) debt to GDP & $r_{d, o}$ & 0.0 \\
Real interest rate on public domestic debt & $r_{d c, o}$ & 5.2 \\
Real interest rate on public concessional debt & $\mathfrak{s}_{o}$ & 0.0 \\
Real interest rate on public external debt & $\tau_{o}^{c}$ & 12.5 \\
Disaster fund savings to GDP & $b_{o}^{*}$ & 37.2 \\
Consumption tax (VAT) rate & & \\
Private external debt to GDP & & \\
& & \\
Calibrated parameters & $\delta_{z i}$ & 6.0 \\
& $\delta_{z a}$ & 3.0 \\
Depreciation rate of standard public infrastructure (\%) & $\varepsilon$ & 0.25 \\
Depreciation rate of adaptation public infrastructure (\%) & $\xi$ & $+\infty$ \\
Additional cost of adaptation public infrastructure & $\xi$ & 5.0 \\
Intertemporal elasticity of substitution in public capital inputs & $\delta_{k}$ & 1.5 \\
Depreciation rate of private capital (\%) & $g$ & \\
Trend per capita growth rate (\%) & &
\end{tabular}

\footnotetext{
${ }^{6}$ In the absence of specific information, we used the parameters of the average LIC in the DIG model, most of which were also used in calibrating the DIGNAD model for the case of Vanuatu.
} 
We use debt data provided by the Ministry of Finance of St. Lucia to set the initial values of public domestic, $b_{o}$, external commercial, $d_{o}$, and concessional debt, $d_{c, o}$, which amounted to 67.7 percent of GDP in 2016. This data source suggests that the real interest rate on concessional debt is zero while the real interest rates on domestic and commercial debt were 5.2 percent. The initial tax rate on consumption is 12.5 percent (the current Value Added Tax rate on most non-exempted goods) while the private sector's initial debt to GDP is also taken from January 2018 WEO database. Finally, public capital depreciates at an annual rate of 5 percent while the annual trend growth rate of St. Lucia is set at 1.5 percent.

Parameters that determine the impact of natural disasters are broadly in line with Marto, Papageorgiou, and Klyuev (2017). Adaptation capital better withstands natural disasters than standard infrastructure, hence the former depreciates at a lower annual rate than the latter, i.e. $\delta_{z a}=3 \%$ while $\delta_{z i}=6 \%$. However, the price of investing in resilient capital is 25 percent higher than the price of standard infrastructure $(\varepsilon=0.25)$. Given the assumption of perfect substitutability between standard and resilient public capital $(\xi=+\infty)$, the higher cost of the latter does not make it obvious for a social planner to entirely invest in it, as it would be the case if the two types of public capital had the same price. We then calibrate the feedback parameter in equation (2), $\phi^{\mathfrak{s}}$, such that the savings fund is replenished at the initial level anytime it is used, i.e. $\mathfrak{s}_{t}=\mathfrak{s}_{0}, \forall t$. Finally, the calibration of natural disasters is completed using evidence reported in IMF (2017). On average, each year St. Lucia suffers a loss of public and private capital of 1 percent and 0.5 percent of GDP, respectively, due to natural disasters. We therefore calibrate a continuum of natural disaster shocks that generate the observed yearly losses of public and private capital.

\section{Simulation Results}

\section{Simulations Set-up}

In this section we design the different policies that St. Lucia could implement to cope with natural disasters while achieving the debt-to-GDP target of 60 percent in 2030.To simplify the financing problem, we assume that in year $t-1$, the government receives a grant of 8 percent of initial GDP, which can be used to finance three alternative policies:

- Policy 1: Debt reduction. First, we assume that the government uses the grant to reduce the stock of public debt thus immediately reaching the target of 60 percent of GDP instead of building some form of resilience. ${ }^{7}$ The immediate reduction in public debtto-GDP allows the annual interest rate paid on public debt to be 50 basis points lower. However, investment in standard public infrastructure is kept at the initial level and reconstruction takes place only in the private sector. This policy allows the government to keep the tax rate at a lower level, but the economy experiences higher damages due

\footnotetext{
${ }^{7}$ Recall that we calibrate the initial public debt-to-GDP ratio to 67.7 percent (Table 1), therefore the grant reduces it to 59.7 percent.
} 
to lack of resilience, the government does not intervene to repair damages, and public capital stock deteriorates, leading to large output losses.

Policy 2: Financial protection. Under this policy, the government builds a natural savings fund in the amount of 8 percent of initial GDP. ${ }^{8}$ The fund is then used exclusively to finance the reconstruction of public capital without issuing new debt. The importance of creating such a fiscal buffer is twofold. First, the government has access to the necessary liquidity to rebuild the entire stock of the destroyed public capital, i.e. $\phi^{Z}=1$ in equations (3) and (4). ${ }^{9}$ Moreover, the accumulation of assets reduces net public debt and the sovereign risk premium. We assume that financial protection allows the annual interest rate paid on public debt to be 50 basis points lower than under structural protection. Despite lower government interest payments, tax revenues must increase under this policy to attain the debt target. Owing to the lack of resilient capital, damages from disasters are large, but the rapid reconstruction of standard public capital helps to contain output losses.

Policy 3: Structural protection. As an alternative to reducing public debt or building financial protection, the government has the option to invest the same amount of 8 percent of GDP in adaptation capital. ${ }^{10}$ As under policy 2, the higher starting debt level requires increases in tax revenues to make the debt target. In addition, structural protection does not provide the government with the liquidity required to reconstruct the entire stock of public capital within the year, as it is the case under financial protection, and $\phi^{z}<1$ in equations (3) and (4). However, building resilient capital, despite its higher price, reduces the damages inflicted to the economy by natural disasters and makes private investment more attractive, also contributing to reducing output losses.

We start our analysis by defining a point in the policy space where the government would be indifferent between financial and structural protection. More specifically, we calculate the fraction of destroyed public capital (both standard and adaptation capital) the government should be able to reconstruct under policy 3 to reach the same level of output as under policy 2 after 15 years. This fraction turns out to be $\phi^{z}=0.92$ (the "threshold"). Then we simulate the path of different macroeconomic variables under two different scenarios for values of $\phi^{z}$ above and below the threshold.

\footnotetext{
${ }^{8}$ Guerson (2016) estimates that a savings fund capitalized at 8 percent of GDP and replenished annually with 0.9 percent of GDP would have a 95 percent chance of non-depletion.

${ }^{9}$ For the purpose of comparing policies, we can ignore capacity constraints, which have the same impact on each policy. In the absence of these constraints, a savings fund of this size would ensure that liquidity is available for reconstruction when needed (footnote 10), i.e. $\phi^{z}=1$.

${ }^{10}$ This implies that, in year $\mathrm{t}-1$, the share of adaptation capital in the total stock of public capital is 23.5 percent.
} 


\section{Simulation Results}

Scenario 1: investing in adaptation capital is preferable if the government can rebuild more than 92 percent of the destroyed capital. We start by assuming that, under policy 3 , the amount of public capital that can be reconstructed is 5 percent higher than the threshold of 92 percent (i.e. $\phi^{z}=0.97$ ). Figure 1 shows the paths of key macroeconomic variables under the three alternative policies. Several comments are in order. First, policy 1 (blue line) immediately reduces public debt to the target of 60 percent of GDP, lessening the need for future tax increases. However, with no government efforts to reconstruct, public capital is eroded by natural disasters, and GDP falls by 2.8 percent after 15 years.

\section{Figure 1. Above-Threshold Public Capital Reconstruction}
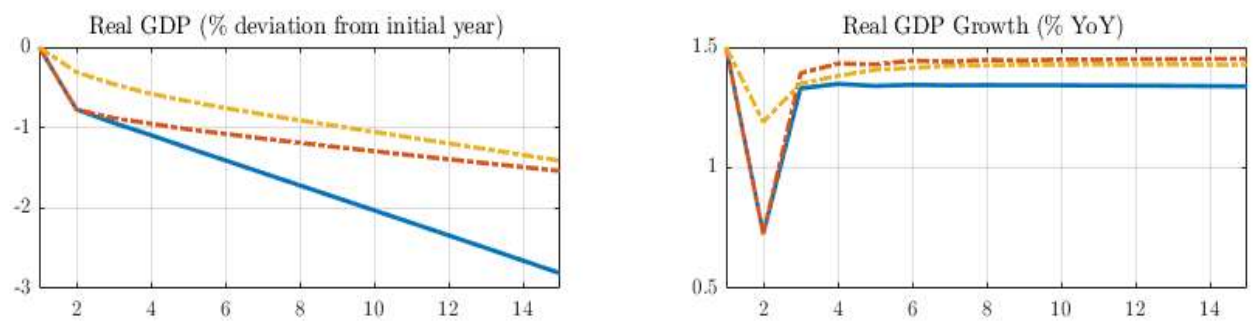

Public Standard Infrastructure Investment (\% of GDP)
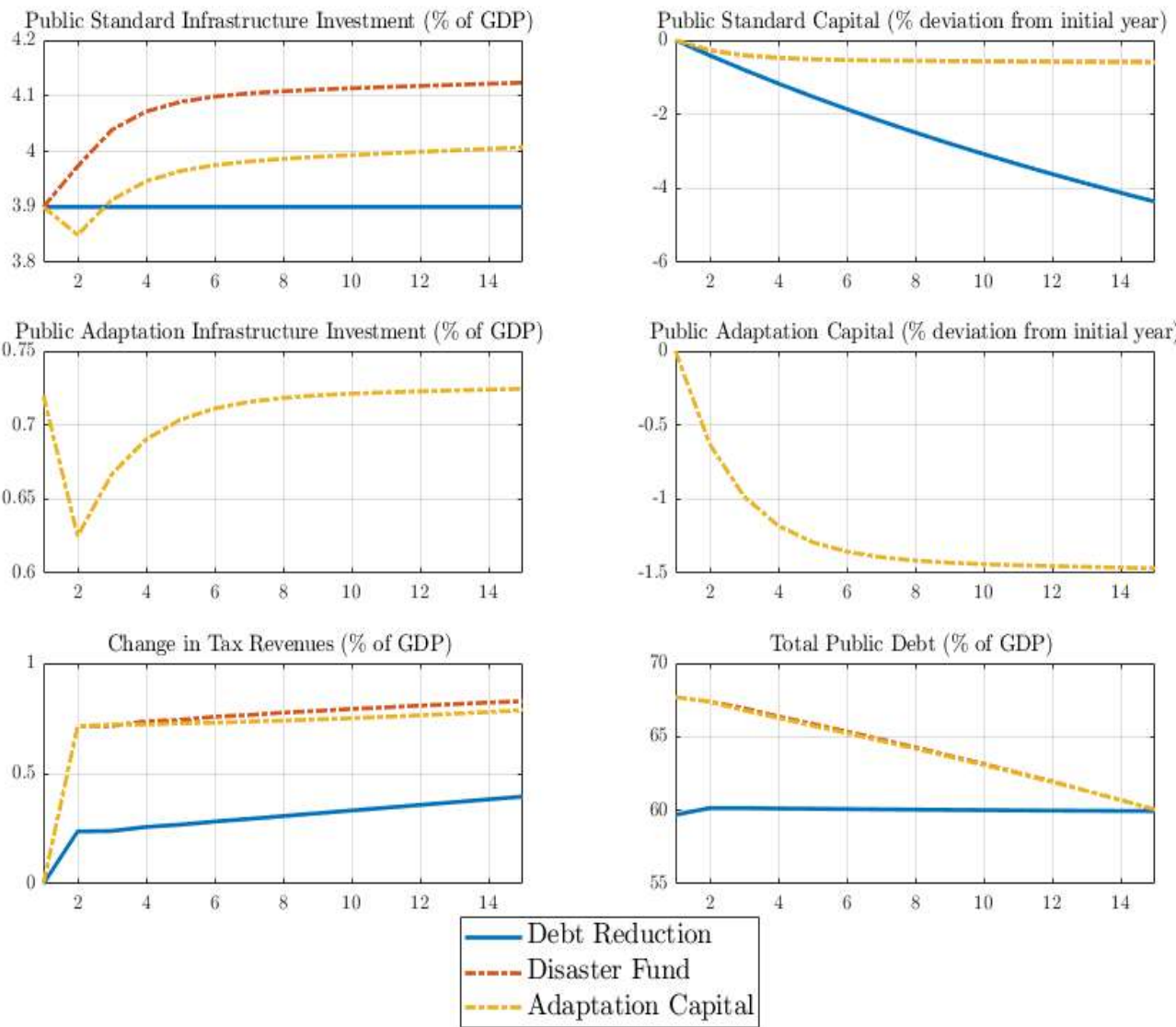
As a consequence, tax revenues need to increase to keep public debt stable in terms of GDP. Conversely, policies to build resilience, although costlier in terms of tax increases, help contain the erosion of public capital and the loss in output, which is limited to some 1.5 percent over 15 years, with a net gain over policy 1 of about 0.1 percent per year, both in terms of level of GDP and GDP growth. ${ }^{11}$ When the government uses the initial grant to build financial protection (policy 2, red line), it has the necessary liquidity to promptly reconstruct the destroyed public capital. Note that the stock of public standard capital stabilizes at a lower level due to the continuous shocks hitting the economy. In practice, the government replaces the destroyed capital but, at the end of the same period, a new shock hits, hence the stock of public standard capital stabilizes at a lower level. ${ }^{12}$ After 15 years, GDP is about 1.5 percent lower while tax revenues increase by 0.8 percent of GDP. The lower sovereign risk premium mitigates the necessary increase in tax revenues and hence prevents a further loss in output. Finally, investing in adaptation capital (policy 3, yellow line) leads to the lowest output loss among the three policies (about 0.13 percent smaller than under policy 2 ). Indeed, the joint effect of lower damages provided by the stock of resilient capital and the capacity to reconstruct almost the entire stock of public capital make this policy preferable. It also follows that the required increase in tax revenues to GDP is slightly lower than under financial protection ( 0.7 percent). Indeed, lower depreciation and higher return of adaptation capital outweigh the higher cost of capital and the liquidity provided by the savings fund.

Scenario 2: investing in adaptation capital is less preferable if the government reconstructs less than 92 percent of the destroyed capital. We now assume that the government's ability to reconstruct public capital under policy 3 is 5 percent lower than the threshold of 92 percent (i.e. $\phi^{z}=0.87$ ). Figure 2 plots the paths of the same macroeconomic variables under policy 1 (blue line) and policy 2 (red line) as in Figure 1. The tighter constraint on the government's ability to reconstruct public capital under policy 3 (yellow line) leads to a lower GDP level than under policy 2 , with a loss of about 1.7 percent after 15 years compared to a loss of 1.55 percent under policy 2 . Indeed, despite the lower damages suffered by the economy, the constraints on public capital reconstruction make structural protection a less preferable option, thus reversing the conclusions drawn under the previous scenario.

\footnotetext{
${ }^{11}$ Note that we assume the economy grows at a steady rate of 1.5 percent per year independently of natural disasters. Figures 1 and 2 therefore show how the growth rates deviate from the long-term growth of the economy due to natural disasters.

${ }^{12}$ Given that under policy 3 the government reconstructs almost the entire stock of public capital (97 percent), the deviations of public standard capital from the initial year almost perfectly overlap with those under policy 2 (see Figure 1, right-panel of second row) although they are slightly larger.
} 


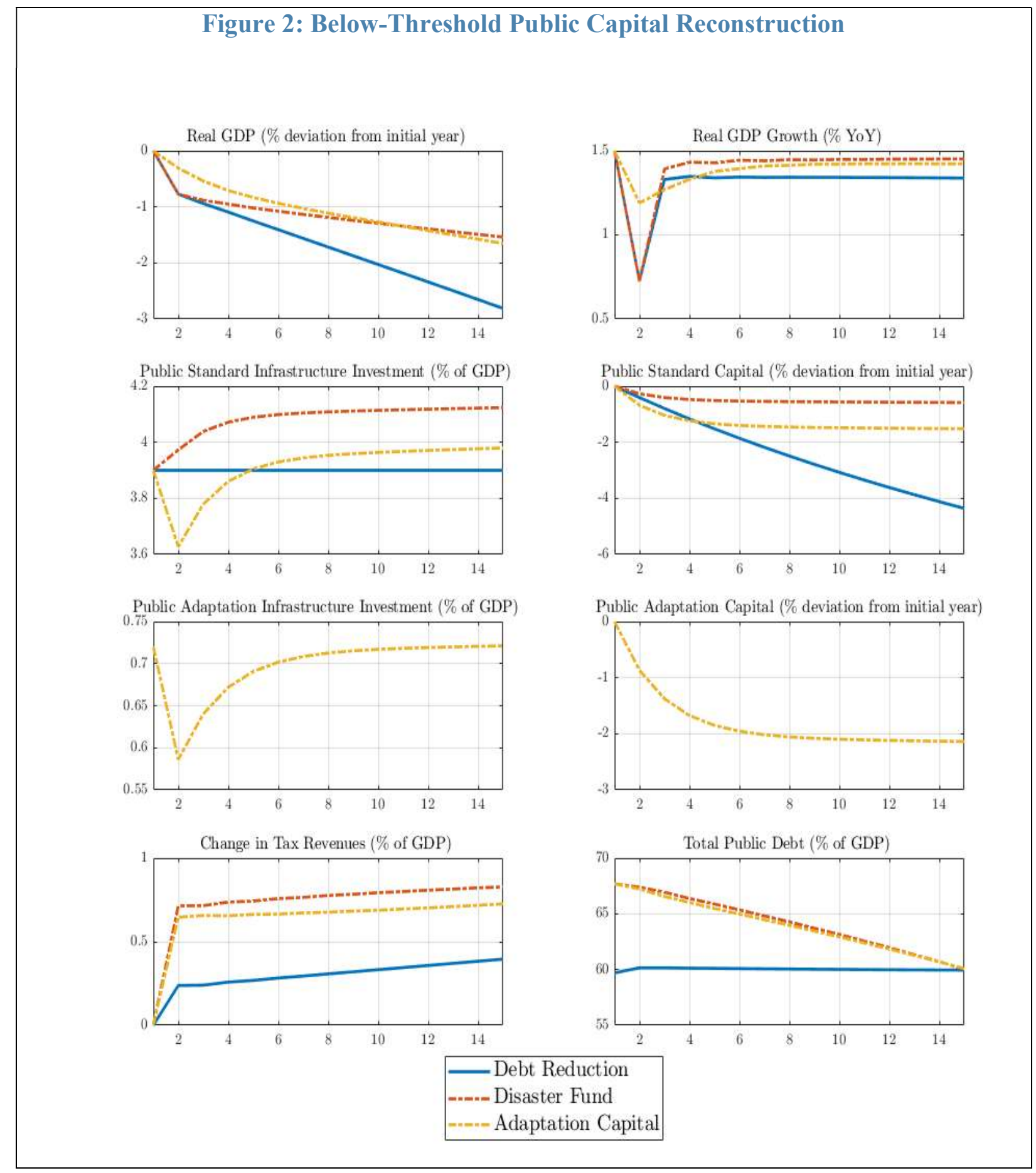

\section{Sensitivity Analysis}

In this section we check how the output payoff of the different policies and the threshold of public capital reconstruction are sensitive to four assumptions made in the baseline calibration. First, we no longer assume that building financial protection lowers St. Lucia's sovereign risk premium. Second, we assume that under structural resilience, public 
investment efficiency is lower. Third, we no longer make investment in resilient infrastructure more expensive than standard infrastructure. Fourth, we calibrate the depreciation rate of public resilient capital to be equal to that of standard public capital. Fifth, we change the calibration of the shocks by allowing for less frequent albeit more powerful natural disasters. In general, the threshold is slightly sensitive to these changes although the qualitative insights about the policy trade-offs continue to hold.

\begin{tabular}{|ll|}
\hline \multicolumn{1}{|c|}{ Table 4: Sensitivity of results to alternative calibrations } \\
Calibration & $\overline{\boldsymbol{\phi}}^{\mathbf{z}}$ \\
\hline Policy 2: no gain in sovereign risk premium & 0.875 \\
Policy 3: lower public investment efficiency & 0.980 \\
Policy 3: same price of public standard and resilient capital & 0.850 \\
Policy 3: same depreciation rate of public standard and resilient capital & 0.960 \\
All policies: Natural disasters every five years & 0.917 \\
\hline
\end{tabular}

The same sovereign risk premium across the two alternative policies lowers the threshold to 87.5 percent. Assuming that building a savings fund does not lower the sovereign risk premium by 50 annual basis points implies that, when investing in adaptation capital, the government should be able to reconstruct 87.5 percent of the destroyed public capital to make the two policies equivalent. Intuitively, removing one of the advantages provided by financial protection implies that a lower fraction of public capital needs to be reconstructed to make investing in adaptation capital reach the same output after 15 years.

Lower public investment efficiency under the investment in adaptation capital policy makes the trade-off more severe. We assume that when the government invests in adaptation capital, public investment efficiency is 1.5 percent lower than when it invests in the disaster fund. Indeed, the lack of available liquidity may make the process of rebuilding the public capital stock slower and less efficient. The implied threshold increases from 92 to 98 percent, so that the government should be capable of rebuilding almost the entire fraction of the destroyed public capital to be indifferent between policies 2 and 3 .

The same price of public standard and resilient capital lowers the threshold to 85 percent. When the price of resilient capital is no longer higher than the price of standard infrastructure (i.e. $\varepsilon=0$ ), the government should be able to rebuild 85 percent of the destroyed public capital stock to be indifferent relative to building financial resilience. Intuitively, it is cheaper for the government to invest in resilient capital, therefore the stock of public capital is higher and the damages suffered by the economy are lower, thus relaxing the trade-off between structural and financial resilience. 
Increasing the depreciation rate of adaptation capital slightly raises the threshold. Finally, we assume that public standard and adaptation capital display the same annual depreciation rate of 6 percent. This implies that each year, the fraction of adaptation capital that needs to be replaced for reasons other than natural disasters is higher. It follows that, with respect to the baseline calibration, an additional fraction of capital needs to be reconstructed following a natural disaster, hence the calculated threshold increases to 96 percent.

Larger more infrequent disasters lower the threshold to 91.7 percent. We calibrate the shocks to occur every five years rather than each year, while still leading to the same average annual damages to public and private capital stocks. In other words, the once-in-five-years disasters are in effect five times larger than the yearly natural disasters calibrated in the baseline model. The results do not seem to hinge on the assumptions about size and frequency of natural disasters.

Furthermore, under Policy 1 (debt reduction) we have relaxed the assumption that the government does not engage in any effort to reconstruct the destroyed public capital, but we allow for full reconstruction financed by taxes. Figure 3 shows that under this scenario (reddashed line), output losses are mitigated (after 15 years the output loss is reduced from 2.81 percent to 2.51 percent) relative to the baseline scenario of debt reduction only (blue-solid line) despite the higher tax revenues needed to finance the reconstruction. However, the output loss is still about twofold that suffered under any of the two forms of resiliencebuilding policies. 


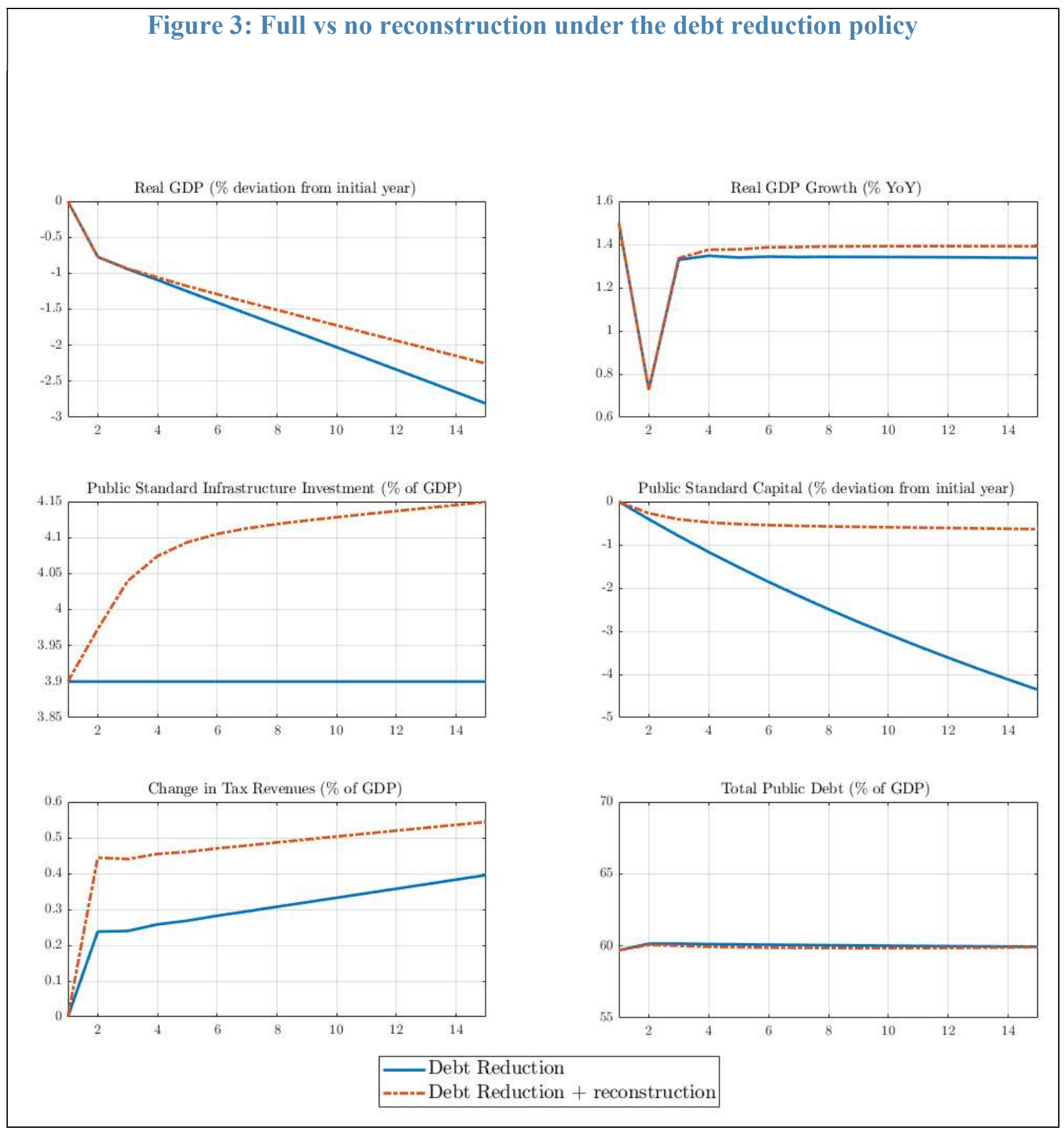

\section{Conclusions}

Building resilience with both structural protection and financial protection is key to cope with natural disasters. Resilient public capital softens the impact of natural disasters on the economy and crowds in private sector investment. Financial tools provide resources for immediate relief and reconstruction after a natural disaster and improve the net asset position 
of the government. In our simulations, based on a dynamic general equilibrium model calibrated to the St. Lucian economy, these strategies are clearly superior to a do-nothing approach where extra resources are used to repay government debt rather than invested in building resilience. The do-nothing approach delivers worse macroeconomic outcomes, with large permanent losses of capital, output, and growth. Both financial protection and structural protection reduce output losses by 1.5 percent over a 15 -year period, raising output growth by 0.1 percent per year.

Our simulations highlight non-trivial trade-offs in building resilience to natural disasters. If the government is not subject to financial constraints and can reconstruct at least 92 percent of the destroyed public capital, structural protection is the best strategy because of its ability to reduce damages from natural disasters and climate change and to improve investment conditions for the private sector. However, if countries have limited fiscal space, are constrained in their ability to borrow, and cannot rely on external grant financing for reconstruction, the availability of liquidity to finance reconstruction is crucial. Under these conditions, the benefits of a speedier reconstruction prevail, and financial protection is the preferred strategy. Low efficiency of public investment would further tilt the balance in favor of financial protection. Overall, the results suggest that the optimal strategy to build resilience is a mix between financial protection and structural protection where the former would have priority under conditions of financial constraints and low public investment efficiency, but investment in resilience is superior at the margin. 


\section{REFERENCES}

Acevedo, S., 2016, "Going with the Wind: Estimating Hurricane and Climate Change Costs in the Caribbean", IMF Working Paper 16/199, International Monetary Fund, Washington, DC.

Acevedo, S., Mrkaic, M., Novta, N. Pugacheva, E., and P. Topalova, 2018, "The Effects of Weather Shocks on Economic Activity: What Are the Channels of Impact?", IMF Working Paper 18/144, International Monetary Fund, Washington, DC.

Bevan, D. and C. Adam, 2016, "Financing the Reconstruction of Public Capital after a Natural Disaster", World Bank Policy Research Working Paper 7718, World Bank, Washington, DC.

Borenzstzein, E. Cavallo, E. and O. Jeanne, 2017, “The Welfare Gains from MacroInsurance Against Natural Disasters", Journal of Development Economics, Vol. 124, pp. 142-156.

Buffie, E., Berg, A., Pattillo, C., Portillo, R., and L.F. Zanna, 2012, "Public Investment, Growth, and Debt Sustainability: Putting Together the Pieces", IMF Working Paper 12/144, International Monetary Fund, Washington, DC.

De Janvry, A., del Valle, A. and E. Sadoulet, 2016, "Insuring Growth: The Impact of Disaster Funds on Economic Reconstruction in Mexico", World Bank Policy Research Working Paper 7714, World Bank, Washington, DC.

Guerson, A., 2016, “Assessment of Government Self-Insurance Needs Against Natural Disasters: An Application to the ECCU”, Eastern Caribbean Currency Union, 2016 Discussion of Common policies of Member Countries, Annex VIII, IMF Country Report No. 16/333, International Monetary Fund, Washington, DC.

International Monetary Fund, 2016, “Small States' Resilience to Natural Disasters Climate Change-Role of the IMF", International Monetary Fund, Washington, DC.

International Monetary Fund, 2017, “St. Lucia - Staff Report for the 2017 Article IV Consultation", Country Report No. 17/76, International Monetary Fund, Washington, DC.

International Monetary Fund -World Bank, 2018, “St. Lucia: Climate Change Policy Assessment-Pilot”, Country Report No. 18/181, International Monetary Fund, Washington, DC.

Marto, R., Papageorgiou, C., and V. Klyuev, 2017, "Building Resilience to Natural Disasters: An Application to Small Developing States", IMF Working Paper 17/223, International Monetary Fund, Washington, DC 